\title{
Study of Thermal Stability of Ultrafine-Grained Copper by means of Electron Back Scattering Diffraction
}

\author{
Ondřej Man ${ }^{1}$, Libor Pantělejev ${ }^{1}$ and Ludvík Kunz ${ }^{2}$ \\ ${ }^{1}$ Institute of Materials Sciences and Engineering, Faculty of Mechanical Engineering, Brno University of Technology, \\ Technická 2896/2, 61669 Brno, Czech Republic \\ ${ }^{2}$ Institute of Physics of Materials, Academy of Sciences of Czech Republic, Žižkova 22, 616 62, Brno, Czech Republic
}

\begin{abstract}
Thermal stability of ultrafine-grained (UFG) structure of $99.9 \%$ pure copper produced by eight equal channel angular pressing (ECAP) passes was studied. The annealing experiments were conducted at $180^{\circ} \mathrm{C}$ in a tube furnace under argon as a covering gas. The dwell times were in the range of $10 \mathrm{~min}$ to $120 \mathrm{~min}$. The electron backscattering diffraction (EBSD) analyses were performed before and after annealing at exactly the same area in order to quantify the degree of decomposition of the UFG structure. Definition of grain boundaries was based on the misorientation angle of $1^{\circ}$. More advanced analysis of the EBSD results based on a kernel average misorientation (KAM) parameter was performed. Inverse pole figure maps with included grain networks did not reveal any substantial changes of UFG microstructure due to annealing. Some shift in the KAM modus in comparison with the initial state was observed but its magnitude was found negligible. Also changes in texture were found to be minor. On the other hand the microhardness increases with increasing time of annealing.

[doi:10.2320/matertrans.MC200909]
\end{abstract}

(Received July 24, 2009; Accepted October 13, 2009; Published January 25, 2010)

Keywords: ultra-fine grained copper, thermal stability of microstructure, electron backscattering diffraction, grain size, texture

\section{Introduction}

Equal channel angular pressing (ECAP) is one of the progressive methods of severe plastic deformation (SPD) used for enhancement of material properties via grain refinement. ${ }^{1)}$

One of the frequently discussed problems is the stability of ultra-fine grained (UFG) structures. It has been shown that the grain boundary structure of different materials is sensitive to elevated temperatures. ${ }^{2,3)}$ The information on the stability of UFG microstructures is still quite sparse. There is number of opened questions like these regarding the details of mechanism of grain coarsening.

The grain coarsening of UFG structures generally occurs at elevated temperatures. ${ }^{4)}$ The formation of bimodal structure was reported as well as changes in texture and an increase of low angle grain boundary (LAB) fraction in contrast to the amount of the high angle grain boundaries (HAB). These changes in microstructure result in changes of mechanical properties like microhardness, tensile characteristics and fatigue life. $^{2-5)}$

The degree of "temperature effect" depends on the magnitude of strain imposed during the SPD process, i.e. on the number of passes through ECAP die and on the temperature of annealing. The dwell time at elevated temperature also results in changes of microstructure and in the related changes of properties attained during the SPD process. $^{2)}$

There is no clear explanation of the temperature effect on UFG structure. It seems that the predominant role is played by the material purity, because alloying stabilizes the microstructure of UFG materials processed by ECAP. 6 ,7) On the other hand impurities in UFG materials are undesirable for many applications. ${ }^{8)}$ Other factors, which may play a role, are the details of UFG microstructure, particularly the grain boundaries, which may vary according to the ECAP process.
For the characterization of microstructure, the EBSD technique beyond transmission electron microscopy (TEM) has been often used. ${ }^{9)}$ EBSD analysis in material research is predominantly focused on changes of misorientation between adjacent analysed points which enables to characterize misorientation redistribution after thermal exposition. ${ }^{10)}$ The kernel average misorientation analysis is increasingly applied for evaluation of average lattice distortion over given perimeter, i.e. for the representation of local strain. ${ }^{11)}$

The best method for evaluation of the changes taking place during thermal exposition is the observation "in situ", but this approach requires highly specific equipment and is thus rarely used so far. ${ }^{12)}$

Data from "ex situ" EBSD analysis are usually acquired from different areas of the same specimen and subsequently compared. This approach can lead to misinterpretation of the real state of microstructure, because the microstructure of severely plastically deformed material is inherently inhomogeneous. That is why detailed EBSD analysis (especially texture analysis, calculation of grain size, misorientation angle distribution, KAM etc.) is definitely more accurate when performed at the same defined place before and after exposition. ${ }^{13)}$ This approach can eliminate inaccuracy caused by heterogeneity of UFG structures. Necessary prerequisite is to inspect sufficiently large area for this type of analysis.

The aim of the present paper is to examine the sensitivity of the UFG structure of copper produced by ECAP to grain growth during thermal exposition using EBSD analysis of the specific area on the specimen to eliminate sources of experimental errors due to material inhomogeneity.

\section{Experimental Details}

UFG copper of commercial purity $(99.9 \%)$ was used in this study. The chemical composition is given in Table 1. Cylindrical billets of $20 \mathrm{~mm}$ in diameter and $120 \mathrm{~mm}$ in length were processed by eight passes of ECAP using route 
Table 1 Chemical composition of UFG $\mathrm{Cu}$.

\begin{tabular}{|c|c|c|c|c|c|c|c|c|c|c|c|}
\hline \multirow{2}{*}{$\mathrm{Cu}$, no less than } & \multicolumn{11}{|c|}{ Impurity $(\%)$, no more than } \\
\hline & $\mathrm{Bi}$ & $\mathrm{Sb}$ & As & $\mathrm{Fe}$ & $\mathrm{Ni}$ & $\mathrm{Pb}$ & $\mathrm{Sn}$ & $\mathrm{S}$ & $\mathrm{O}$ & $\mathrm{Zn}$ & $\mathrm{Ag}$ \\
\hline $99.9 \%$ & 0.001 & 0.002 & 0.002 & 0.005 & 0.002 & 0.005 & 0.002 & 0.004 & 0.05 & 0.004 & 0.003 \\
\hline
\end{tabular}

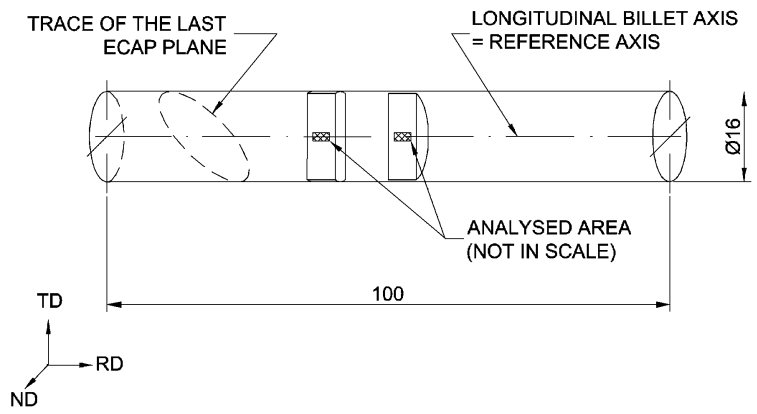

Fig. 1 Billet of UFG Cu with typical positions of extraction of specimens. System of coordinates as defined in the EBSD software.

$\mathrm{B}_{\mathrm{C}}{ }^{14)}$ at the laboratory of prof. R. Z. Valiev, Institute of Physics of Advanced Materials, Ufa State Aviation Technical University, Russia. After ECAP, the billets were turned to $16 \mathrm{~mm}$ diameter and $100 \mathrm{~mm}$ length, Fig. 1.

The ultimate tensile strength and the yield stress of UFG $\mathrm{Cu}$ determined on four specimens were $\sigma_{\mathrm{UTS}}=387 \pm 5 \mathrm{MPa}$ and $\sigma_{0.2}=375 \pm 4 \mathrm{MPa}$ respectively.

Specimens with cross section approximately $4 \times 4 \mathrm{~mm}$ and length of $10-16 \mathrm{~mm}$ were machined from the billets. Specimen surface, parallel to the longitudinal axis of the billet, was carefully mechanically and finally electrolytically polished to enable the EBSD application. Electropolishing was performed in phosphoric acid-ethanol-water-isopropyl alcohol solution at $10 \mathrm{~V}$ with holding time of $60 \mathrm{~s}$. The temperature of the electrolyte varied between 9 and $13^{\circ} \mathrm{C}$.

Annealing experiments were conducted at $180^{\circ} \mathrm{C}$ in tube furnace under argon as a covering gas. The dwell times were in the range of 10 to $120 \mathrm{~min}$. Temperature of the sample was controlled by Pt 100 thermal probe immersed into a shallow bore inside a specimen. Specimens were inserted to the preheated furnace and then, upon reaching the required temperature of the specimen, the dwell time was measured. After thermal exposition the specimens were cooled down in cold zone of the tube by the argon flow.

The EBSD analyses were made before and after annealing at specific area in order to quantify the degree of decomposition of the UFG structure. EBSD analyses were carried out with a Philips XL 30 scanning electron microscope with EBSD detector (TSL). Area of EBSD scans was $30 \times 60 \mu \mathrm{m}$ with $0.15 \mu \mathrm{m}$ step. The grain sizes were calculated as diameter of a circle with the same area as the observed grain.

Before and after thermal exposition the microhardness $\mathrm{HV}_{0.3}$ (using a $0.3 \mathrm{~kg}$ load) was measured for evaluation of the changes in mechanical properties during annealing.

\section{Results}

Figure 1 shows schematic drawing of positions of the samples inside the billet together with the system of coordinates chosen for EBSD analyses. The microstructure of the UFG $\mathrm{Cu}$ as observed by means of EBSD is presented in Fig. 2. Microstructure of as-pressed sample, Fig. 2(a), in terms of the inverse pole figure map with included grain network shows combination of elongated small and large grains. Grain boundaries are characterized by the chosen misorientation angle of $1^{\circ}$. Average grain size is $0.714 \mu \mathrm{m}$. The same area of the specimen after thermal exposition at $180^{\circ} \mathrm{C}$ for $120 \mathrm{~min}$ dwell time is shown in Fig. 2(b); the average grain size is $0.755 \mu \mathrm{m}$. The color code for both inverse pole figure maps is in Fig. 2(c).

It is evident from the comparison of images before and after exposition that thermal exposition did not result in any substantial grain growth, only moderate redistribution of misorientation inside individual grains occurred. Microstructure after thermal exposition seems to be rather finer.

Figure 3 shows the microhardness evolution with increasing dwell time. The hardness rises with increasing annealing time. Depicted points represent average values of 10 measurements of microhardness across the sample surface. The hardness tends to saturate with increasing time and after $120 \mathrm{~min}$ the average microhardness reaches the value of about $128 \mathrm{HV}_{0.3}$.

Grain size distribution in as-pressed state and after thermal exposition at $180^{\circ} \mathrm{C}$ for $120 \mathrm{~min}$ is presented in Fig. 4. The maximum area fraction in both cases belongs to the grain size class with diameter $0.625 \mu \mathrm{m}$; the respective area fraction being 0.137 for non-annealed state and 0.12 for the annealed one. This redistribution of grain size with respect to the area fraction is similar for all investigated dwell times (10, 30, 60 and $120 \mathrm{~min}$ ) at chosen temperature. Only slight changes in grain size class occupancy for larger diameters were observed. Annealing of UFG $\mathrm{Cu}$ at $180^{\circ} \mathrm{C}$ did not cause evolution of bimodal structure for all investigated dwell times.

The distribution of misorientation angles and kernel average misorientation before and after exposition for $120 \mathrm{~min}$ is presented in Figs. 5 and 6. Performed analysis shows that there are no significant changes in misorientation angles after thermal exposition. The small differences in distributions, which can be observed, lie within the scatter of the measurement accuracy. Generally, it can be concluded that the $\mathrm{LAB}$ (less than $15^{\circ}$ ) or $\mathrm{HAB}$ fraction (more than $15^{\circ}$ ) remains constant.

Kernel average misorientation distribution was calculated for non-annealed and annealed state. For given pixel (kernel center) the average misorientation of that point with respect to its second nearest neighbors was calculated. KAM maximum of $3^{\circ}$ was set for the calculation since higher values were proven unnecessary. This gave us an image of local lattice distortions within $0.3 \mu \mathrm{m}$ radius around each kernel center. Results of KAM analyses for $120 \mathrm{~min}$ dwell time are shown in Fig. 6. The distribution of kernel average 

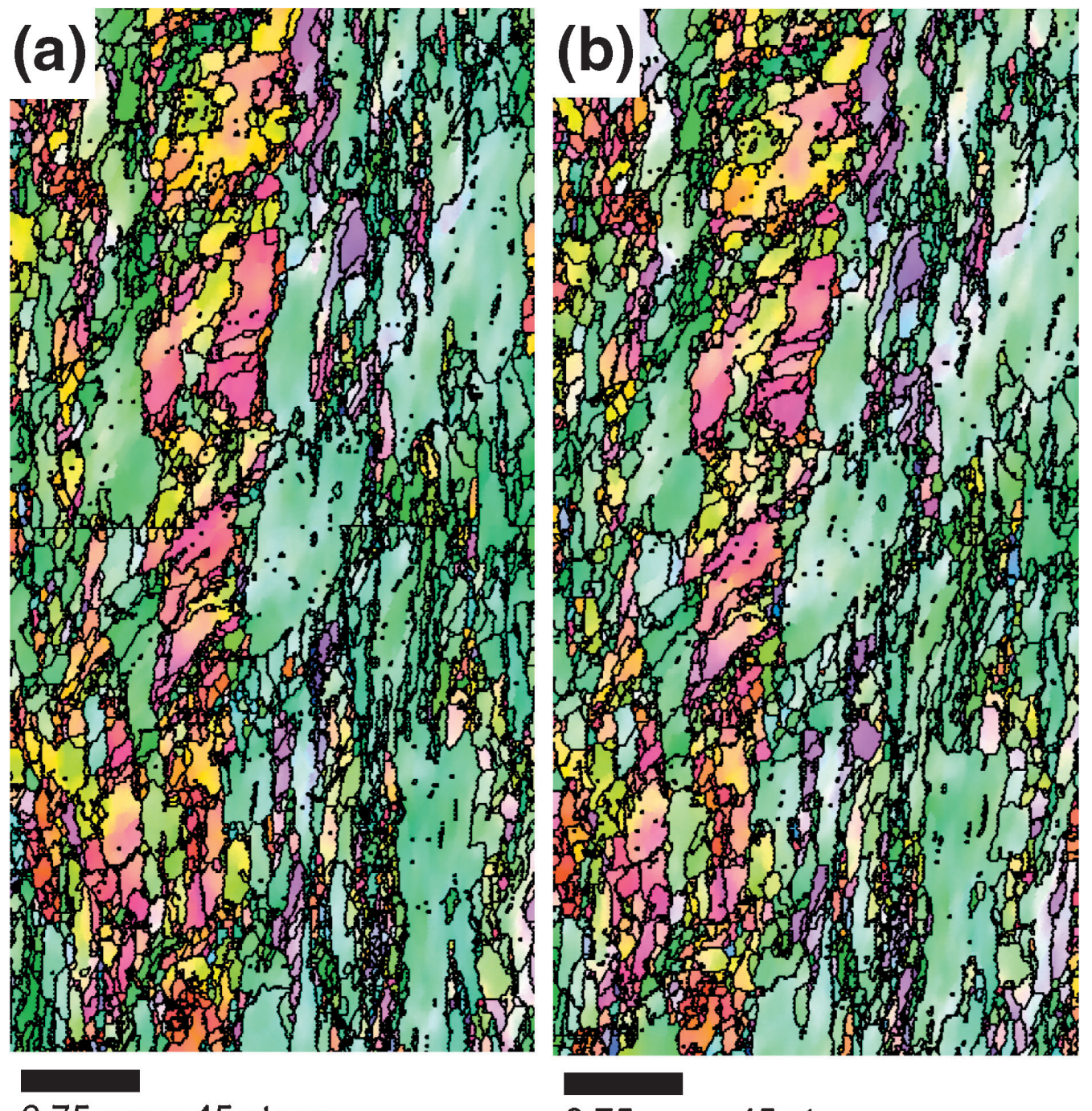

$6.75 \mu \mathrm{m}=45$ steps

$6.75 \mu \mathrm{m}=45$ steps

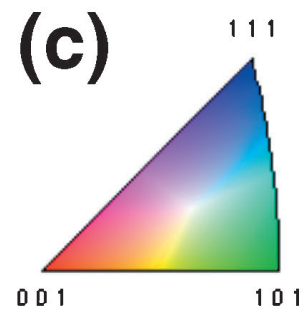

Fig. 2 Comparison of UFG microstructure in (a) as-pressed state and (b) after thermal exposition at $180^{\circ} \mathrm{C} / 120 \mathrm{~min} / \mathrm{argon}$ in terms of inverse pole figure maps (grain boundary network included) for longitudinal axis of billet, (c) color code for inverse pole figure maps.

misorientation is practically the same for both observed states for all investigated annealing times.

For detailed discovery of microstructural changes during thermal exposition, the texture analyses by means of EBSD were performed. Slight weakening of the texture achieved during ECAP process was observed after annealing for all selected dwell times. In Figs. 7 and 8 the textures in terms of inverse pole figures before and after annealing are shown for the case of 120 min dwell time. Several maxima can be seen in the texture: the (416) plane normal is aligned with "rolling direction" (RD) (i.e. longitudinal billet axis, Fig. 1), the (111) plane normal is aligned with "transverse direction" and (748) plane normal with "normal direction" (ND). Because the microstructure of the billet after ECAP process is heterogeneous, the most pronounced planes in texture figures are different for each sample (Fig. 1). However comparison of the defined "specific area" on a single sample in nonannealed and annealed states gives qualitatively reliable view onto the texture evolution.

\section{Discussion}

Microstructural stability of UFG materials during thermal exposition is one of the most important limitations to their wider engineering application. There is no doubt that the grain coarsening of UFG $\mathrm{Cu}$ deteriorates mechanical proper- 


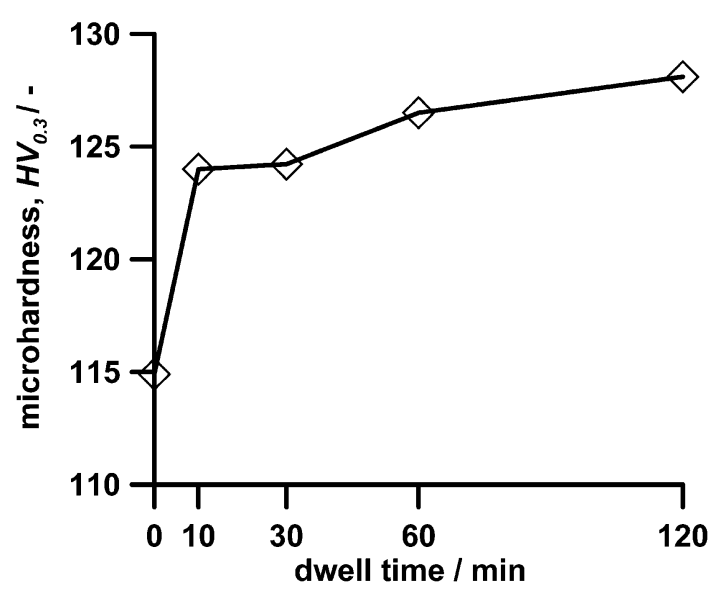

Fig. 3 Evolution of microhardness after annealing at $180^{\circ} \mathrm{C}$.

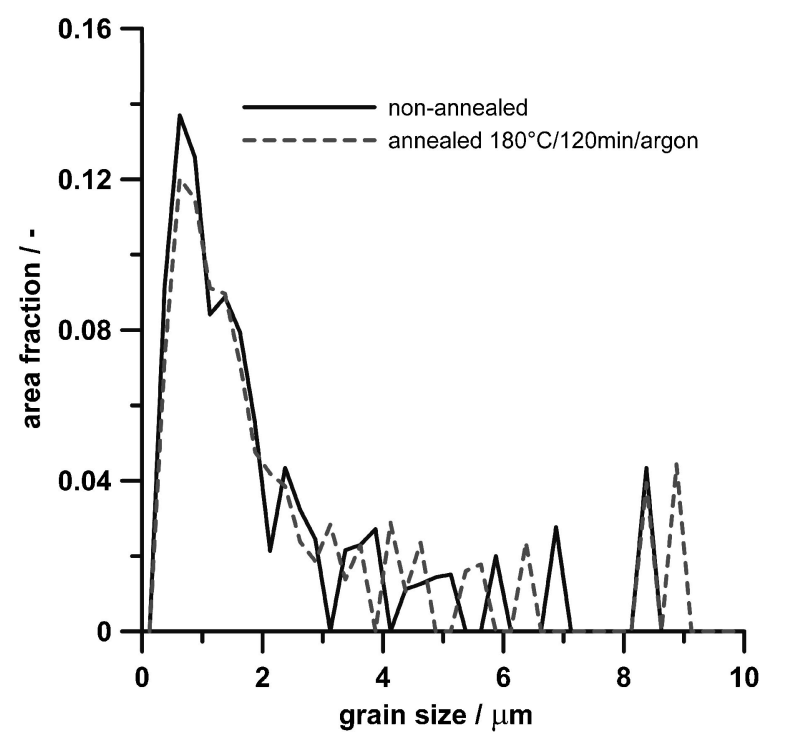

Fig. 4 Grain size distribution before and after thermal exposition.

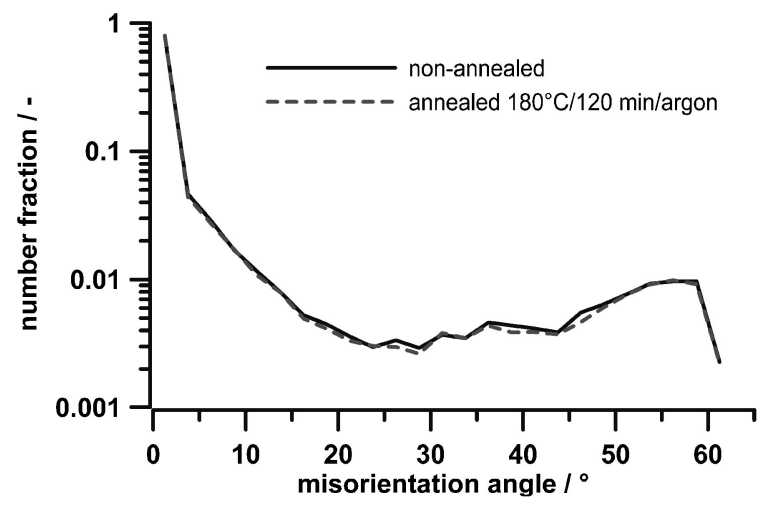

Fig. 5 Misorientation angle distribution in as-pressed state and after annealing.

ties. Nevertheless, the explanation of the mechanisms of UFG microstructure coarsening and conditions under which the coarsening takes place are not clear. Moreover, the literature data are controversial. Thermal exposition up to $150^{\circ} \mathrm{C}$ was reported as not relevant to the grain growth; related microstructural changes are minor. ${ }^{15}$ Insensitivity

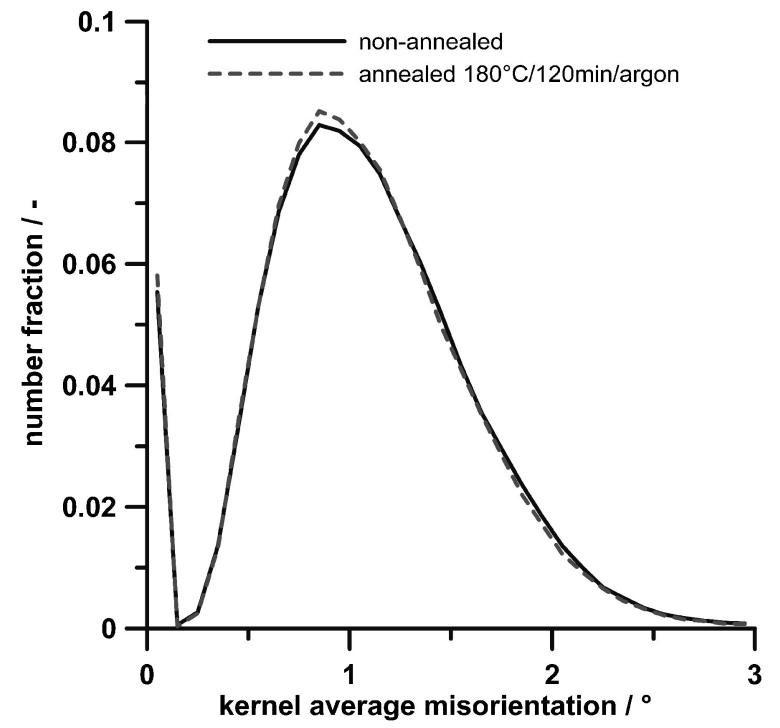

Fig. 6 Kernel average misorientation distribution before and after annealing.
[100]

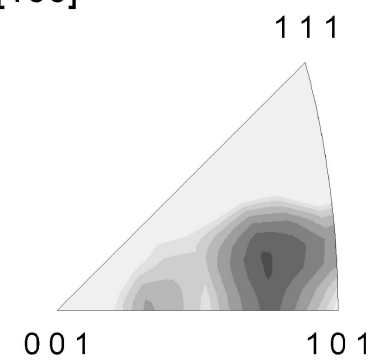

[001]

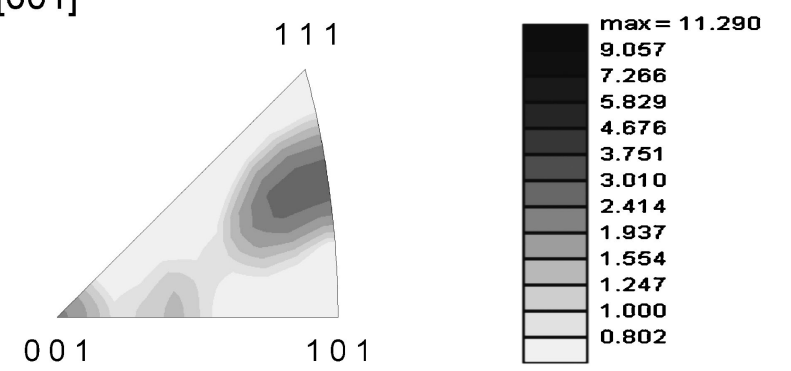

Fig. 7 Texture in terms of inverse pole figures (as-pressed state) with texture intensity scale. $[100]=\mathrm{RD},[010]=\mathrm{TD},[001]=\mathrm{ND}$.

of mechanical properties of ECAPed $\mathrm{Cu}$ up to $260^{\circ} \mathrm{C}$ was found in Ref. 5). On the other hand, Molodova et al. ${ }^{2,16)}$ found that annealing at $150^{\circ} \mathrm{C}$ for 2 min caused grain growth and evolution of bimodal structure; the decrease of microhardness was revealed already above $100^{\circ} \mathrm{C}$ after $10 \mathrm{~min}$ annealing. This is in agreement with the experiments of Höppel et al. ${ }^{3)}$ where the development of bimodal structure at $170^{\circ} \mathrm{C}$ was observed.

Results of the present work show that annealing at $180^{\circ} \mathrm{C}$ does not result in any development of bimodal structure, i.e. there is no substantial local grain coarsening. Contrary to the results of Molodova et al., ${ }^{16)}$ who found considerable decrease of microhardness at $150^{\circ} \mathrm{C}$ already after $100 \mathrm{~s}$, the microhardness increase with longer dwell time on the temperature $180^{\circ} \mathrm{C}$ was observed in the present study. 
[100]

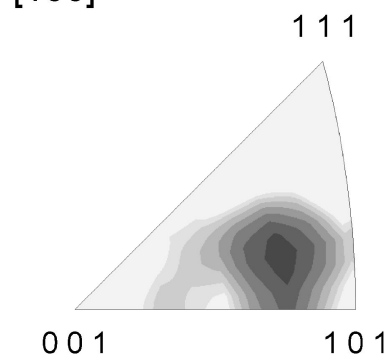

[001]

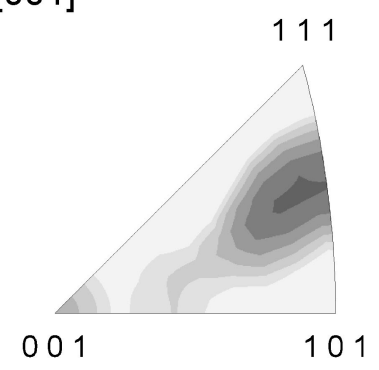

[010]

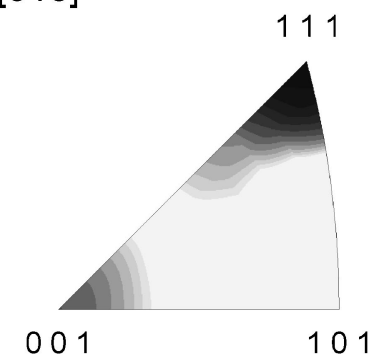

001

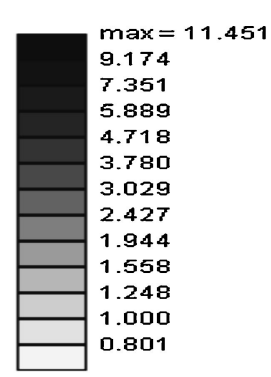

bonding procedure) or disks (for high pressure torsion procedure). That is why it is important to choose more complex approach to microstructure evaluation and the "specific area method" seems to be the proper way, as also used in Ref. 13).

\section{Conclusions}

(1) The microhardness of ultra fine-grained $\mathrm{Cu}$ increases during annealing up to $120 \mathrm{~min}$ at $180^{\circ} \mathrm{C}$ in Ar.

(2) Electron backscattering diffraction analysis revealed no grain growth after exposition at $180^{\circ} \mathrm{C}$ for 10 up to $120 \mathrm{~min}$.

(3) Changes in misorientation angle distribution are not significant for examined dwell times.

(4) Local lattice distortion evaluated from kernel average misorientations is qualitatively on the same level before and after thermal exposition.

(5) Only moderate changes in texture were observed after heating in comparison with as-pressed state.

Fig. 8 Texture in terms of inverse pole figures (annealed state $180^{\circ} \mathrm{C} /$ $120 \mathrm{~min} /$ argon) with texture intensity scale. $[100]=\mathrm{RD},[010]=\mathrm{TD}$, $[001]=$ ND.

Simultaneously, only very moderate changes (in the frame of the scatter of experimental data) in misorientation angle and grain size distribution were detected. Detailed KAM analysis revealed that the local distortion of lattice is qualitatively the same and the thermal exposition does not substantially change the KAM. Based on this, it could be concluded that annealing at investigated dwell times at $180^{\circ} \mathrm{C}$ rather improved the hardness and did not deteriorate the UFG microstructure. Only slight weakening of texture achieved by ECAP process was found after annealing. This is in contrast with results of Etter et al., ${ }^{17)}$ showing pronounced changes in texture as observed by EBSD already after $7 \mathrm{~min} 30 \mathrm{~s}$ annealing at $200^{\circ} \mathrm{C}$.

From the comparison of present results with literature data it follows that UFG $\mathrm{Cu}$ prepared by ECAP can exhibit differences as regards the stability of structure. One reason could be the influence of material purity on its behavior. This was suggested in Ref. 18); the UFG $\mathrm{Cu}$ of low purity exhibited better fatigue properties than UFG $\mathrm{Cu}$ of high purity. Another reason for different behavior can be sought in details of grain boundary structure. The UFG materials contain large volume fraction of grain boundaries which play more important role than in the case of conventionally grained metals. The yield stress is a function of nucleation conditions of dislocations at grain boundaries ${ }^{19}$ ) which can substantially differ according to the details of ECAP conditions (ECAP rate, temperature, size of billets etc.). The observed increase of microhardness due to annealing can be explained by rearrangement of grain boundary structure, which cannot be observed by EBSD technique, but which can influence the conditions for dislocation movement and related mechanical properties, like hardness.

Materials prepared by severe plastic deformation often exhibit inhomogeneous microstructure in the whole volume of billets (in the case of ECAP), strips (accumulated roll-

\section{Acknowledgement}

This work was financially supported by the Ministry of education, youth and sports, under the contract 2E08017 and a project 1QS200410502 of the Academy of Sciences of the Czech Republic. This support is gratefully acknowledged.

\section{REFERENCES}

1) V. M. Segal: Mater. Sci. Eng. A 197 (1995) 157-164.

2) X. Molodova, G. Gottstein and R. J. Hellmig: Mater. Sci. Forum 558559 (2007) 259-264.

3) H. W. Höppel, M. Brunnbauer, H. Mughrabi, R. Z. Valiev and A. P. Zhilyaev: Proc. Materialsweek 2000, (Available from http://www. materialsweek.org/proceedings/).

4) R. K. Islamgaliev, F. Chmelik and R. Kuzel: Mater. Sci. Eng. A 237 (1997) 43-51.

5) T. Kravchenko, A. Korshunov, N. Zhdanova, L. Polyakov and I. Kaganova: Mater. Sci. Forum 584-586 (2008) 960-965.

6) S. Lee, M. Furukawa, Z. Horita and T. G. Langdon: Mater. Sci. Eng. A 342 (2003) 294-301.

7) K. Neishi, Z. Horita and T. G. Langdon: Mater. Sci. Eng. A 352 (2003) 129-135.

8) Y. Amouyal, S. V. Divinski, L. Klinger and E. Rabkin: Acta Mater. 56 (2008) 5500-5513.

9) A. J. Wilkinson and P. B. Hirch: Micron. 28 (1997) 279-308.

10) W. Q. Cao, A. Godfrey, W. Liu and Q. Liu: Mater. Sci. Eng. A 360 (2003) 420-425.

11) H. Li, E. Hsu, J. Szpunar, H. Utsunomiya and T. Sakai: J. Mater. Sci. 43 (2008) 7148-7156.

12) O. V. Rofman, P. S. Bate, I. Brough and F. J. Humphreys: J. Microscopy 233 (2009) 432-441.

13) H. Kimura, Y. Kojima, Y. Akiniwa, K. Tanaka and T. Ishida: Key Eng. Mater. 340-341 (2007) 943-948.

14) K. Nakashima, Z. Horita, M. Nemoto and T. G. Langdon: Mater. Sci. Eng. A 281 (2000) 82-87.

15) J. Lian, R. Z. Valiev and B. Baudelet: Acta Metall. Mater. 43 (1995) 4165-4170.

16) X. Molodova, G. Gottstein, M. Winning and R. J. Hellmig: Mater. Sci. Eng. A 460-461 (2007) 204-213.

17) A. L. Etter, D. Solas, T. Baudin and R. Penelle: Mater. Sci. Forum 495497 (2005) 845-850.

18) P. Lukáš, L. Kunz and M. Svoboda: Kovove Mater. 47 (2009) 1-9.

19) G. Saada: Mater. Sci. Eng. A 400-401 (2005) 146-149. 